\title{
PERANCANGAN SISTEM DENGAN METODE WATERFALL PADA APOTEK XYZ
}

\author{
Sofiansyah Fadli', Sunardi² \\ 1,Teknik Informatika, STMIK Lombok, 2,Teknik Informatika, Universitas Atma Jaya Yogyakarta \\ 1,Jln. Basuki Rahmat No.105 Praya Lombok Tengah 83511 \\ 2,Janti, Caturtunggal, Kec. Depok, Kabupaten Sleman, Daerah Istimewa Yogyakarta 55281, \\ 1, sofiansyah182@gmail.com, 2, ,soenardhi.75@gmail.com,
}

\begin{abstract}
Trade in the world the accuracy of the information is very needed, Especially information on the selling price, the price of basic supplies and sales of the rest of the administrative system accuracy in sales because the relationship between companies look to affect consumer as well as administrative systems sales in the company itself.An apothecary the goddess of a trading companies that move in the field of trade of various types of medication.The writer observes that the system the administration of the sale in pharmacies goddess is still done manually.During an apothecary rely more on this management in the price of memory, but not all the price of drugs could be remembered by employees so that employees often see a list price when there was a transaction. In addition to that employees have to see a list of supplies or cards supplies books to know the drug supplies. The research uses a method of structured approach that is used diagrams the current data (DAD) , entity relationship diagram (ERD), between advance design and implementation of, the making of the application of a system of the sale of the drug in the design a groove the system uses microsoft office visio 2007 as a medium to design a diagram a groove, a diagram the context, relation between entity and design page interface. On the implementation system using programming borland delphi 7 to design a display interface, and for data storage use mysqldatabase by using application sqlyog enterprise This system is the most effective pharmaceutical sales of data. By using a computerized system to ease the officer to use the data in accordance with the service.To reduce the level of the errors that does not want it is to be used as a medium for managing data to simplify and reduce the cost of the data.
\end{abstract}

Keywords : Analysis System, Design System, Computerized, Waterfall Method

\begin{abstract}
Abstrak
Pada dunia perdagangan, keakuratan informasi sangatlah dibutuhkan,terutama informasi mengenai harga jual, Harga Pokok Penjualan dan sisa persediaan dalam sistem administrasi penjualan karena keakuratan informasi-informasi tersebut mempengaruhi hubungan perusahaan terhadap konsumen serta sistem administrasi penjualan pada perusahaan itu sendiri. Apotek adalahsuatu perusahaan dagang yang bergerak di bidang perdagangan berbagai jenis obat-obatan. Penulis mengamati bahwa sistem administrasi penjualan di Apotek masih dilakukan secara manual. Selama ini manajemen apotek lebih mengandalkan ingatan dalam menghapalkan harga, namun tidak semua harga obat dapat diingat oleh karyawan sehingga karyawan sering melihat daftar harga ketika terjadi transaksi. Selain itu karyawan harus melihat buku daftar persediaan atau kartu persediaan untuk mengetahui persediaan obat tersebut. Cara ini kurang efisien, karena banyak waktu yang terbuang untuk melihat harga obat pada daftar harga dan persedian pada kartu persediaan setiap kali transaksi. Metode penelitian menggunakan pendekatan terstruktur yaitu menggunakan Diagram Arus Data (DAD), entity relationship diagram (ERD), Perancangan Antar Muka dan Implementasi, Pembuatan aplikasi sistem penjualan obat ini dalam perancangan alur sistemnya menggunakan Microsoft Office Visio 2007 sebagai media untuk mendesain diagram alur, diagram konteks, relasi antar entitas dan desain halaman antarmuka aplikasnya. Pada implementasi sistem menggunakan pemrograman Borland Delphi 7 untuk desain tampilan antarmuka, dan untuk penyimpanan data menggunakan database MySQL. Sistem ini merupakan media yang efektif dalam pengelolaan data penjualan obat. Dengan pemanfaatan sistem yang terkomputerisasi mempermudah petugas dalam mengelola data
\end{abstract}


sesuai dengan bagian dan jabatannya. Dapat mengurangi tingkat kesalahan yang tidak dikehendaki dalam sistem ini sudah sangat layak untuk dimanfaatkan sebagai media untuk mengelola data untuk mengurangi terjadinya kecurangan dan mempermudah pemeliharaan datanya..

Kata kunci : Analisis Sistem, Perancangan Sistem, Komputerisasi, Metode Waterfall

\section{Pendahuluan [Cambria10, bold]}

Pada dunia perdagangan, keakuratan informasi sangatlah dibutuhkan, terutama informasi mengenai harga jual, Harga Pokok Penjualan dan sisa persediaan dalam sistem administrasi penjualan karena keakuratan informasi-informasi tersebut mempengaruhi hubungan perusahaan terhadap konsumen serta sistem administrasi penjualan pada perusahaan itu sendiri. Keakuratan informasi untuk konsumen bertujuan untuk memenuhi kebutuhan konsumen akan informasi tertentu misalnya, harga produk sedangkan untuk perusahaan sendiri bertujuan mengetahui apakah sistem administrasi penjualan berjalan dengan baik. Penulis melakukan penelitian pada beberapa Apotek yangsuatu perusahaan dagang yang bergerak di bidang perdagangan berbagai jenis obat-obatan. Penulis mengamati bahwa sistem administrasi penjualan di Apotek tersebut masih dilakukan secara manual. Selama ini manajemen apotek lebih mengandalkan ingatan dalam menghapalkan harga, namun tidak semua harga obat dapat diingat oleh karyawan sehingga karyawan sering melihat daftar harga ketika terjadi transaksi. Selain itu karyawan harus melihat buku daftar persediaan atau kartu persediaan untuk mengetahui persediaan obat tersebut. Cara ini kurang efisien, karena banyak waktu yang terbuang untuk melihat harga obat pada daftar harga dan persedian pada kartu persediaan setiap kali transaksi. Dengan uraian dan latar belakang di atas, maka penulis tertarik melakukan penelitian dengan judul Rancang Bangun Sistem Penjualan Obat Pada Apotek XYZ dengan menggunakan metode waterfall.

\section{Tinjuan Pustaka}

Penelitian sebelumnya merupakan sumber referensi sekaligus acuan penulis untuk membangun Sistem Dengan Metode Waterfall Pada Apotek XYZ diantaranya penelitian (Deni Eka Purwanto, 2012) dengan judul Pembangunan Sistem Informasi Apotek Pink Pacitan. Salah satu apotek yang mengatur manejemen secara konvensional yakni mengolah data dengan mencatat pada pembukuan, dan belum memanfaatkan teknologi komputer secara optimal. Dalam transaksi penjualan obat dilakukan diatas secarik kertas sebelum dimasukkan ke dalam buku laporan. Sistem ini dirancang dengan menggunakan MySQL.

Penelitian selanjutnya dilakukan oleh (Nurdiansyah dan Triyono, 2013) Pada apotek Perwira Jaya, masih banyak permasalahan pada proses pengolahan data penjualan obat, salah satu penyebabnya karena transaksi masih dilakukan secara konvensional sehingga berdampak terhadap keterlambatan di dalam penyampaian suatu data informasi, baik kepada pemilik apotek maupun kepada konsumen. Hasil dari penelitian ini adalah untuk memberikan kemudahan dalam proses pengolahan data apotek, seperti data obat, data penjualan obat, pembuatan kuitansi, pembuatan laporan kepada pimpinan dan untuk mempermudah dalam proses pencarian data selain itu memiliki media penyimpanan yang lebih efektif dan lebih besar".

Astuti (2012) dalam jurnal yang berjudul "Sistem Informasi Penjualan Obat Pada Apotek Jati Farma Arjosari" menguraikan tentang toko obat (apotek) Jati Farma Arjosari yang menggunakan cara konvensional untuk mengerjakan tugastugas yang berkaitan dengan apotek. Apotek ini memiliki permasalahan paa pencatatan transaksi yang bersifat konvensinal. Dalam penelitiannya Puspita Dwi Astuti membuat sistem pencatatan obat (pembelian-penjualan) yang bersifat komputersasi. Manfaatnya adalah agar memudahkan proses pencatatan data obat, baik itu pembelian ataupun penjualan. Metode yang digunakan adalah kepustakaan, observasi, wawancara dan analisis. Dari pembuat sistem ini, harapannya bisa meringankan tugas asisten apoteker dan membuat kinerja apotek menjadi lebih efektif dan efisien.

Mujiati (2016) dalam jurnal yang berjudul "Analisi Dan Perancangan Sistem Informasi Stok Obat Pada Apotek Arjowinangun" dijelaskan bahwa proses yang ada diantaranya adalah 
pengolahan data obat, proses pengolahan data masih bersifat manual dan membutuhkan waktu yang sangat lama. Metode yang digunakan adalah interview (wawancara) langsung ke lapangan dan dengan mengumpulkan data-data yang akan digunakan dalam proses perancangan. Pengembangan sistem masih menggunakan metode terstruktur, yaitu DFD, EER, dan ERD belum ada metode dengan menggunakan bahasa pemrograman Visual Basic.

\subsection{Analisis Sistem}

Menurut John W. Satzinger (2009), Analisis sistem (System Analysis) dapat didefinisikan sebagai penguraian dari suatu sistem informasi yang utuh kedalam bagian-bagian komponen dengan maksud untuk mengidentifikasi dan mengevaluasi permasalahan-permasalahan, kesempatan-kesempatan, hambatan-hambatan yang terjadi dan kebutuhan-kebutuhan yang diharapkan sehingga dapat diusulkan perbaikanperbaikannya. Tahap analisis sistem dilakukan setelah tahap perencanaan sistem (System Planing) dan sebelum tahap desain sisem (System Design)

Tahap analisis merupakan tahap yang kritis dan sangat penting, karena kesalahan di dalam tahap ini akan menyebabkan jugakesalahan di tahap selanjutnya. Misalnya anda dihadapkan pada sustu sistem untuk menentukan seberapa jauh sistem tersebut telah mencapai sasarannya.Jika sistem ini mempunyai beberapa kelemahan, anda harus dapat menemukannya.Tugas yang diilustrasikan ini adalah yang disebut dengan analisis sistem. Istilah analisis sistem ini memang tepat, karena memang itulah yang akan dikerjakan oleh analisis sistem dalam tahap ini yaitu menganalisa sistem untuk menemukan kelemahan-kelemahan sehingga dapat diusulkan perbaikannya.

\subsection{Pengertian Apotek}

Berdasarkan Peraturan Pemerintah No.51 tahun 2009, tentang Pekerjaan Kefarmasian yang dimaksud dengan Apotek adalah suatu sarana pelayanan kefarmasian tempat dilakukannya praktek kefarmasian oleh apoteker.

\subsection{Analisis dan Perancangan}

Kenneth E. Kendal (2010), menyatakan analisis dan perancangan sistem berupa menganalisis input data atau alir data secara sistematis, memproses atau mentranformasikan data, menyimpan data, dan menghasilkan output informasi. Selanjutnya digunakan untuk menganalisis, merancang dan mengimplementasikan peningkatan-peningkatan fungsi bisnis yang bias dicapai melalui penggunaan sistem informasi terkomputerisasi. Langkah-langkah analisis sistem antara lain sebagai berikut:

1. Mengidentifikasi masalah

2. Memahami sistem kerja yang ada

3. Menganalisa sistem

4. Membuat laporan hasil analis

\subsection{Penjualan}

Definisi penjualan menurut Mulyadi (2008), penjualan merupakan kegiatan yang dilakukan oleh penjual dalam menjual barang atau jasa dengan harapan akan memperoleh laba dari adanya transaksi-transaksi tersebut dan penjualan dapat diartikan sebagai pengalihan atau pemindahan hak kepemilikan atas barang atau jasa dari pihak penjual ke pembeli.

\subsection{Data Flow Diagram (DFD)}

Merupakan diagram yang menggunakan notasi-notasi untuk menggambarkan arus dari data sistem. DFD sering digunakan untuk menggambarkan suatu sitem yang telah ada atau sistem baru yang akan dikembangkan secara logika tanpa mempertimbangkan lingkungan fisik dimana data tersebut mengalir. Diagram Arus Data (data flow diagram) adalah gambaran grafis yang memperlihatkan aliran data dari sumbernya. Dalam objek kemudian melewati suatu proses yang menstransformasinya ke tujuan yang lain, yang ada pada objek lain (Fatta, 2007).

\subsection{Pengertian Sistem}

Sistem pada dasarnya adalah sekelompok unsur yang erat hubungannya satu dengan yang lain, yang berfungsi bersama-sama untuk mencapai tujuan tertentu. Dari definisi ini dapat dirinci lebih lanjut pengertian sistem secara umum (Sutabri, 1998), yaitu sebagai berikut:

1. Setiap sistem terdiri dari unsur-unsur, unsurunsur suatu sistem terdiri dari subsistem yang lebih kecil, yang terdiri pula dari kelompok unsur yang membentuk subsistem tersebut.

2. Unsur-unsur tersebut merupakan bagian terpadau sistem yang bersangkutan. Unsurunsur sistem berhubungan erat satu dengan yang lain dan sifat serta kerja sama antarunsur sistem tersebut mempunyai bentuk tertentu.

3. Unsur sistem tersebut bekerja sama untuk mencapai tujuan sistem.

4. Suatu sistem merupakan bagian dari sistem yang lain yang lebih besar.

\subsection{Entity Relationship Diagram (ERD)}

Merupakan gambar atau diagram yang menunjukan informasi dibuat, disimpan, dan digunakan dalam sistem bisnis, dimana entitas 
biasanya menggambarkan jenis informasi yang sama yang digunakan untuk menghubungkan antar entitas yang sekaligus menunjukan hubungan antar data (Fatta, 2007).

\subsection{Diagram Context}

Diagram Context (top level) adalah bagian dari data flow diagram yang berfungsi memetakan model lingkungan yang dipresentasikan dengan lingkaran tunggal yang mewakili keseluruhan sistem (Fatta, 2007).

\section{Metodologi Penelitian}

\subsection{Desain Penelitian}

Desain penelitian untuk sistem penjualan obat pada apotek xyz dapat dilihat pada gambar berikut ini:

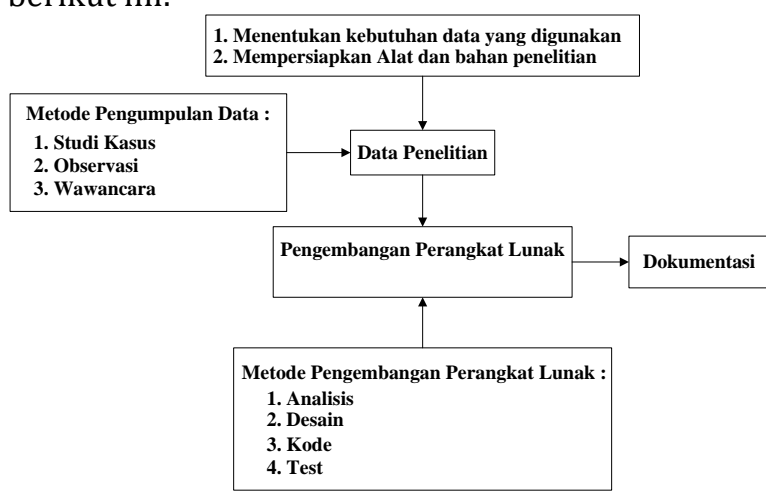

Gambar 3.1 Desain Penelitian

\subsection{Metode Pengumpulan Data}

1. Observasi

Mengamati secara langsung bagaimana sistem yang ada pada Apotek untuk memperoleh data-data dan gambaran yang jelas mengenai objek yang diteliti.

2. Wawancara

Melakukan komunikasi tanya jawab secara langsung dengan Petugas Apotek mengenai datadata yang dibutuhkan oleh penulis untuk membuat sistem ini.

3. Penelusuran Kepustakaan

Menggunakan beberapa buku sebagai referensi, untuk memperoleh penjelasan yang bersifat teori yang berhubungan dengan masalah yang diteliti.

\subsection{Metode Pengembangan Perangkat Lunak}

Pengembangan aplikasi sistem penjualan obat pada apotek xyz menggunakan metode sekuensial linier (waterfall). Pressman (2001), metode Waterfall adalah suatu proses pengembangan perangkat lunak berurutan, di mana kemajuan dipandang sebagai terus mengalir ke bawah (seperti air terjun) melewati fase-fase perencanaan, pemodelan, implementasi (konstruksi), dan pengujian. Berikut adalah gambar pengembangan perangkat lunak berurutan/linear.

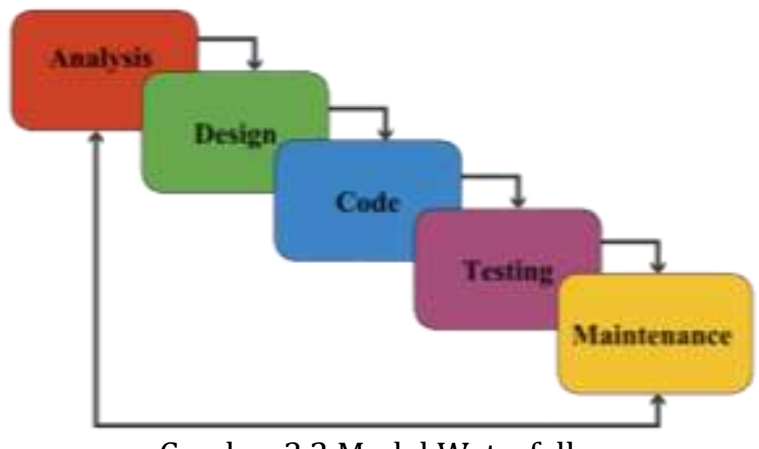

Gambar 3.2 Model Waterfall

\section{Hasil dan Pembahasan}

\subsection{Analisis Kebutuhan Sistem}

Perancangan sistem merupakan kegiatan yang sangat penting dalam menyelesaikan tugas atau masalah terutama dalam pembuatan program sehingga dapat berjalan dengan baik dan lancar.Dalam rancangan suatu sistem dapat menggunakan Diagram Konteks, Diagram Arus Data (DAD) dan Entity Relationsip Diagram (ERD). Model Entity Relational Diagram (ERD) adalah model yang dibuat berdasarkan anggapan bahwa dunia nyata terdiri dari koleksi obyek-obyek dasar yang dinamakan entitas (entity) serta hubungan (relationship) antara entitas-entitas itu.

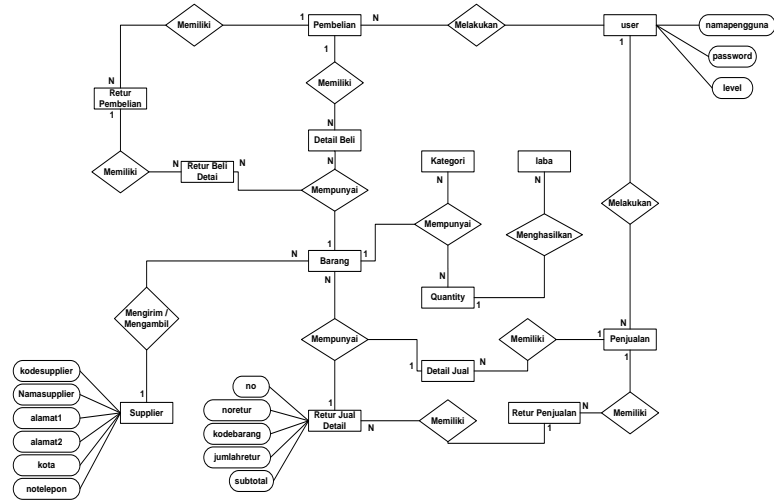

Gambar 4.1 Entity Relationship Diagram (ERD)

Pada sistem yang menggunakan erd diatas data yang di kelola yaitu data user, data barang, data kategori, data supplier, data laba, data quantity, data penjualan, data detail jual, data retur penjualan, data retur jual detail, data pembelian, data detail beli, data retur pembelian dan data retur beli detail. Erd pada apotek di buat berdasarkan kebutuhan dari implementasi sistem apotek yang menggunakannya. Secara garis besar 
prosesnya sama, namun pembedanya adalah proses tambahan yang ada pada masing masing sistem.

\subsection{Perancangan Proses dengan DAD}

Diagram Alir Data merupakan suatu model logika data atau proses yang dibuat untuk menggambarkan darimana asal data dan kemana tujuan data yang keluar dari sistem, dimana data disimpan, proses apa yang menghasilkan data tersebut dan interaksi antara data yang tersimpan dan proses yang terjadi pada data tersebut. Berikut ini merupakan Diagram Alir Data Level 2 transaksi dan manajemen data dari sistem penjualan obat pada apotek xyz.

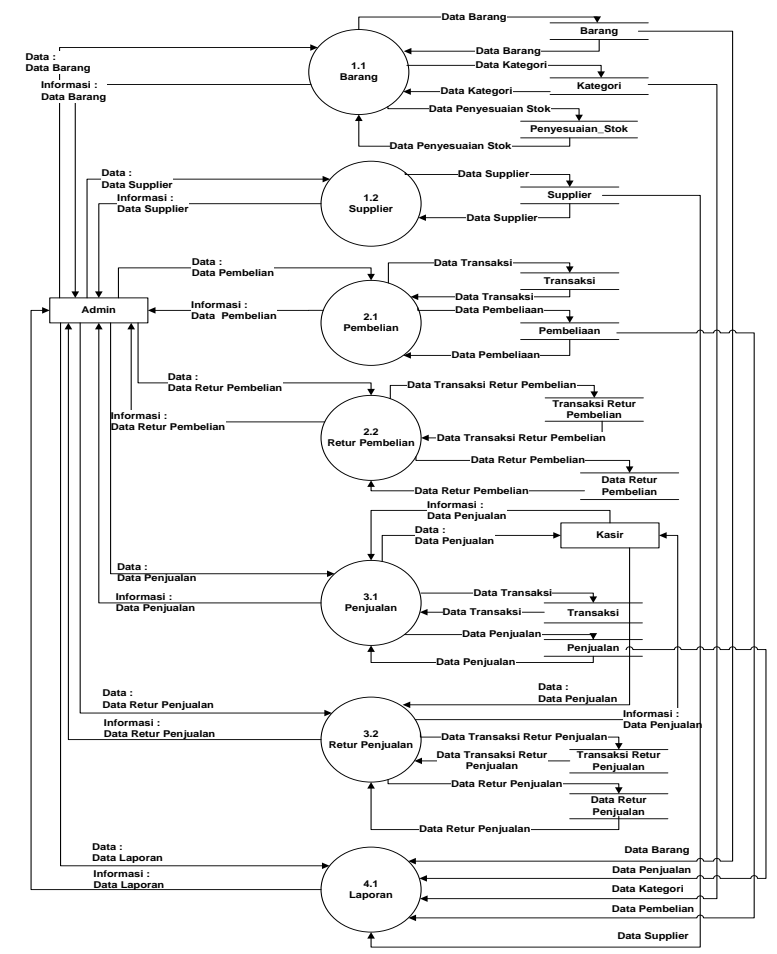

Gambar 4.2 DAD Level 2 Manajemen Data

Beberapa proses pada Diagram Alir Data Level 2 yaitu proses manajemen barang, supplier, pembelian, retur pembelian, penjualan, retur penjualan, dan laporan. beberapa tabel yang digunakan yaitu tabel barang, tabel kategori, tabel penyesuaian stok, tabel supplier, tabel transaksi, tabel pembeliaan, tabel transaksi retur pembelian, tabel data retur pembelian, tabel transaksi, tabel penjualan, tabel transaksi retur penjualan, dan tabel retur penjualan.

\subsection{Implementasi}

Tahap implementasi sistem merupakan tahap meletakan sistem untuk dapat dioperasikan atau digunakan. Sistem penjualan obat yang telah dibangun dilakukan proses pengujian dari modulmodul yang telah dirancang.

A. Menu Utama

Pada menu utama ini terdapat menu toolbar untuk memanggil form menu yang tersedia pada aplikasi. Tampilan menu utama sebagai berikut:

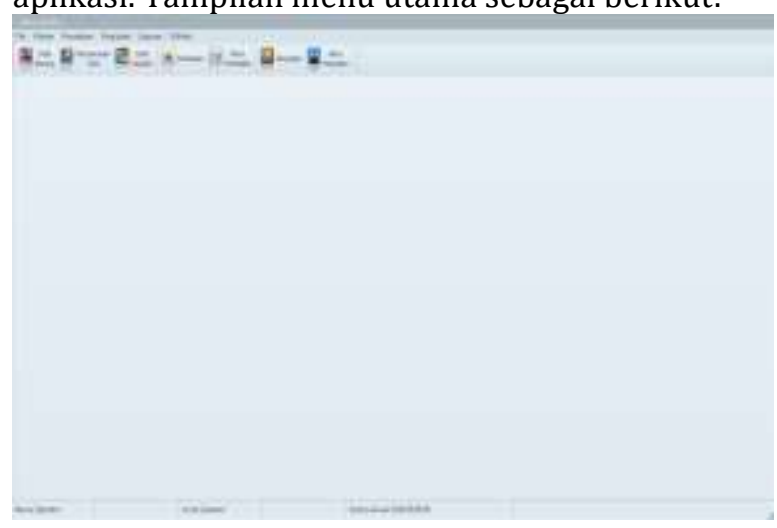

Gambar 4.3 Halaman Utama

Halaman ini berfungsi sebagai halaman induk dari sistem penjualan obat apotek, dimana semua perintah pemanggilan halaman terdapat pada menu halaman utama. Saat pertama kali program dijalankan, kita akan diarahkan terlebih dahulu ke menu login, dengan mengisi usrename dan password dengan benar maka akan masuk kedalam program dengan menu lengkap yang telah tersedia didalam program ini.

\section{B. Supplier}

Pada form supplier berfungsi sebagai tempat menyimpan data-data supplier seperti kode supplier, nama supplier, alamat, kota dan nomer telepon.

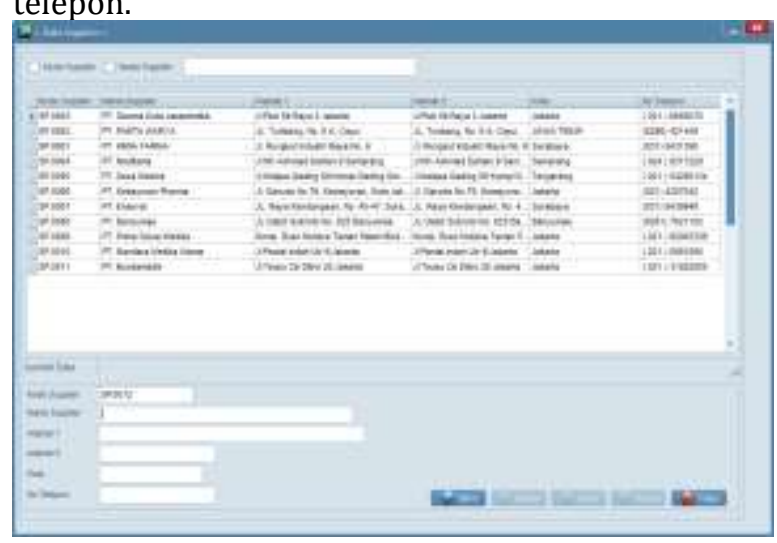

Gambar 4.4 Form Supplier

Pada form menu supplier terdapat tombol simpan yang berfungsi untuk menyimpan data supplier, tombol ubah untuk mengubah data supplier, tombol hapus untuk menghapus data supplier, tombol tutup untuk menutup form supplier dan kembali ke menu utama 
C. Barang

Pada form barang berfungsi sebagai tempat menyimpan data semua obat seperti kode barang, kode barcode, nama barang, kategori, harga beli, harga jual, sisa stok dan stok limit.

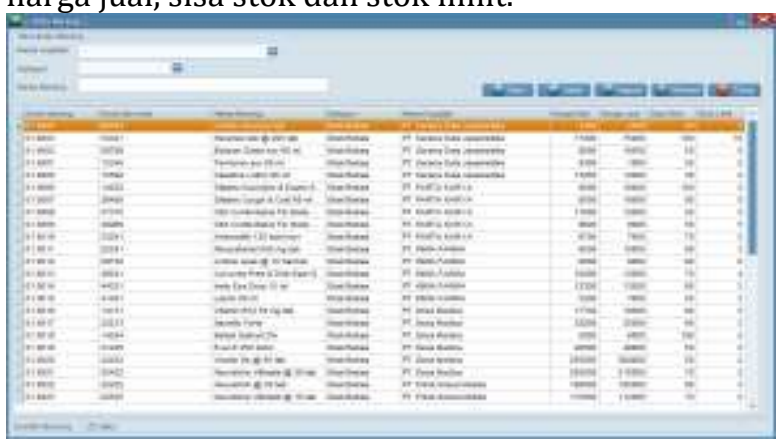

Gambar 4.5 Form Barang

Pada form menu barang terdapat tombol baru yang berfungsi untuk menginput data baru danmenyimpan data barang, tombol ubah yang berfungsi untuk mengubahe data barang, tombol hapus yang berfungsi untuk menghapus data barang, tombol refresh untuk merefresh data yang baru dengan data yang sudah ada dan tombol tutup yang berfungsi untuk keluar dari form barang dan kembali ke menu utama.

D. Menu Transaksi Pembelian

Pada form menu transaksi pembelian berfungsi untuk mencatat dan melakukan transaksi pembelian dari supplier yang dilakukan oleh pihak apotek

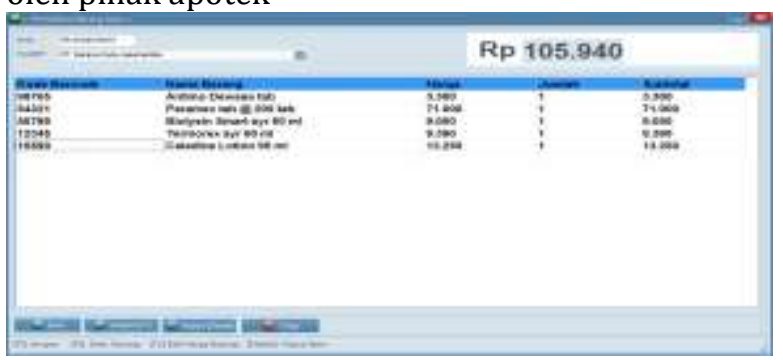

Gambar 4.6 Menu Transaksi Pembelian

Pada form menu pembelian terdapat tombol baru yang berfungsi untuk memasukan data yang baru, tombol simpan yang berfungsi untuk menyimpan data, tombol hapus yang berfungsi untuk menghapus data dan tombol tutup yang berfungsi untuk menutup form menu transaksi, dan tombol-tombol yang berfungsi seperti tombol F1 pada computer untuk menyimpan, tombol F2 edit harga barang, F3 data barang, dan tombol delete untuk menghapus data.

E. Menu Transaksi Penjualan

Pada form menu transaksi penjualan berfungsi untuk mencatat dan melakukan transaksi penjualan barang atau obat yang dilakukan oleh pihak apotek ke konsumen.

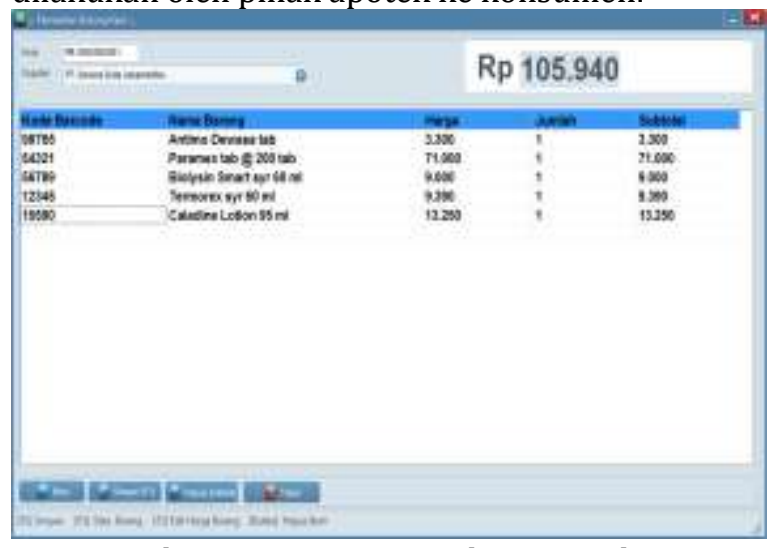

Gambar 4.7 Menu Transaksi Penjualan

Pada form menu penjualan terdapat tombol baru yang berfungsi untuk memasukan data yang baru, tombol simpan yang berfungsi untuk menyimpan data, tombol hapus yang berfungsi untuk menghapus data dan tombol tutup yang berfungsi untuk menutup form menu transaksi, tombol data nota untuk melihat data yang terjual dan tombol-tombol yang berfungsi seperti tombol F1 pada komputer untuk menyimpan, tombol F2 bayar, F3 data barang.

\section{Kesimpulan dan saran}

\subsection{Kesimpulan}

Dengan adanya program aplikasi yang terkompuerisasi dapat membantu mengatasi permasalahan proses pengolahan data pada apotek yang masih menggunakan cara manual untuk melakukan pencatatan data transaksi dan pembuatan laporannya, hal ini dapat mempermudah pengguna terutama bagi kasir dan admin dalam mengelola semua proses transaksi dan laporan pada apotek. Sistem ini akan memudahkan bagi petugas dibagian kasir untuk mengakses data transaksi penjualan, data transaksi pembelian, data supplier, data petugas dan proses pembuatan laporan-laporan sehingga dapat meminimalisir kesalahan atau kekeliruan yang selama ini sering terjadi pada Apotek.

\subsection{Saran}

Adanya pelatihan khusus kepada karyawan untuk meningkatkan skill (keahlian atau ketrampilan) dalam penggunaan aplikasi program komputer agar pembuatan laporan menjadi lebih cepat dan akurat. Perlu adanya pemeliharaan sistem yang baik menyangkut pemeliharaan perangkat keras dan pemeliharaan pengolahan data sistem aplikasi agar dapat digunakan secara maksimal. 


\section{Daftar Pustaka:}

(1) Al Fatta, H. "Analisis Dan Perancangan Sistem Informasi." (2007): Andi. Yogyakarta.

(2) Astuti, P. D. "Sistem Informasi Penjualan Obat Pada Apotek Jati Farma Arjosari", Indonesian Journal on Networking and Security(IJNS), 34 (2012).

(3) Deni Eka Purwanto. "Pembangunan Sistem Informasi Apotek Pink Pacitan", jurnal speed 139 (2012).

(4) Fadli, Sofiansyah. "Model Rapid Application Development Dalam Pengembangan Sistem Reservasi Dan Penyewaan Kamar Hotel." JIRE: Jurnal Informatika \& Rekayasa Elektronika. 1.1 (2018): 57-64.

(5) Harianto, Dkk. "Kepuasan Pasien Terhadap Pelayanan Resep Di Apotek Kopkar Rumah Sakit Budhi Asih", (2005): Modula, Jakarta

(6) Hodia, Maelani, and Khairul Imtihan-STMIK Lombok. "Perancangan Sistem Informasi Praktek Klinik Kebidanan (PKK) Pada Prodi DIII Kebidanan Stikes Qamarul Huda." IJNSIndonesian Journal on Networking and Security 6.3 (2017).

(7) Imtihan, Khairul, Rabiatul Hadawiyah, and Hasyim Asyari-STMIK Lombok. "Sistem Informasi Penggajian Guru Honorer Menggunakan Konsep Agile Software Development dengan Metodologi Extreme Programming (XP) pada SMK Bangun Bangsa." IJNS-Indonesian Journal on Networking and Security 7.2 (2018).
(8) Jogiyanto, H. "Analisis dan Desain Sistem Informasi, Edisi III," (2010): Andi, Yogyakarta.

(9) Kendall, E.Kenneth dan Julie E. Kendall. "Analisis dan Perancangan Sistem".Edisi kelima, Jilid 1. (2010): Indeks, Jakarta.

(10) Khairul Imtihan. "Perencanaan Strategi Sistem Informasi Pendidikan Pada Sekolah Tinggi Manajemen Informatika dan Komputer (STMIK) Lombok." Bianglala Informatika 3.2 (2015).

(11) Mujiati, H. "Pembangunan Sistem Informasi Persediaan Obat Pada Apotek Arjowinangun", Jurnal Bina Nusantara Informatika (LPPM3), 41 (2016).

(12) Mulyadi. "Sistem Akuntansi, Edisi Ketiga, Cetakan Keempat",(2008): Salemba Empat, Jakarta.

(13) Nurdiansyah, Triyono RA. "Pembuatan Sistem Informasi Apotek Berbasis Web Pada Apotek Tulakan", Journal on Networking and Security (IJNS) 23 (2013): 46-50.

(14) Pressman, Roger S. "Software Engineering A Practitioner'sApproach", Edisi kelima. (2001): McGraw-Hill, New York Amerika.

(15) Satzinger, John W. , Jackson, Robert B. \& Burd, Stephen D. "System Analysis and Design in Changing World. 5th Edition". (2009): Course Technology, Cengange Learning, Canada. 